\title{
Temperature dependent measurement of internal damping of austenitic stainless steels
}

\author{
Monika Oravcová ${ }^{1,}$, Peter Palček ${ }^{1}$, Mária Chalupová $^{1}$, Milan Uhríčik $^{1}$ \\ ${ }^{1}$ Department of Materials Engineering, Faculty of Mechanical Engineering, University of Žilina, \\ Univerzitná 8215/1, 01026 Žilina, Slovakia
}

\begin{abstract}
This article is aimed on the analysis of the internal damping changes of austenitic stainless steels AISI 304, AISI 316L and AISI 316Ti depending from temperature. In experimental measurements only resonance method was used which is based on continuous excitation of oscillations of the specimens and the whole apparatus vibrates at the frequency near to the resonance. Microplastic processes and dissipation of energy within the metals are evaluated and investigated by internal damping measurements. Damping capacity of materials is closely tied to the presence of defects including second phase particles and voids. By measuring the energy dissipation in the material, we can determine the elastic characteristics, Youngs modulus, the level of stress relaxation and many other.
\end{abstract}

Keywords: austenitic stainless steels; internal damping; plastic deformation, deformation-induced martensite

\section{Introduction}

Austenitic stainless steels are a class of alloys with a face-centered-cubic lattice structure of austenite which maintains from room temperature (and below) to the melting point. When $18 \%$ chromium and $8 \%$ nickel are added, the crystal structure of austenite remains stable over all temperatures. They are the most widely used grade of stainless steel. These steels have a very good mechanical and technological properties finding widespread not only in industrial, chemical and food applications, but also in medical field. They are corrosion resistant, paramagnetic in the annealed condition, however they can become slightly magnetic after plastic deformation, e.g. after cold working [1,2].

During shaping the component into the desired geometry or shape, steels often undergo a thermomechanical processing which changes the material properties. A material's microchemistry may be changed during thermomechanical processing and its functional properties are changed.

Plastic deformation changes the properties of steels by increasing the dislocation density which affects mainly the mechanical properties and helps in diffusion acceleration, phase transformations, nucleation, etc. During the cold working process, a martensitic phase

\footnotetext{
*Corresponding author: monika.oravcova@fstroj.uniza.sk

Reviewers: Františka Pešlová, Marta Kianicová
} 
called deformation-induced martensite is evoked. The amount of deformation-induced martensite is increasing with severity of deformation.

Cold working and deformation-induced martensite influences the damping properties of austenitic stainless steels. Several damping mechanisms - movement of crystal defects are present in the metallic materials. The damping capacity of the structural material used for various applications is an important property from the fatigue point of view. The internal damping can be defined as the capacity of a material to damp mechanical vibrations. The capacity change of material to damp mechanical vibrations as function of time or temperature corresponds to a structural, microstructural and substructural change [3-5].

\section{Experimental procedures}

\subsection{Experimental material}

For the measurement of internal damping commercially available austenitic stainless steels, namely AISI 304, AISI 316 with low carbon content and AISI 316 stabilized by Ti, were used as an experimental material. The real chemical composition of the experimental material is listed in the Table 1.

The experimental material was submitted to metallographic analysis before the measurement of internal damping. Microstructures of the austenitic stainless steels were analysed in the initial state and are presented on the Fig. 1 - Fig. 3. Metallographic analysis of longitudinal cross-section of the specimen in initial state after chemical etching in $\mathrm{HNO}_{3}+\mathrm{HF}+$ glycerine solution showed that the structure is non-homogeneous and have polyedric austenite grains with different grain sizes and occurrence of annealing twins and deformation martensite after plastic deformation as a result from the final treatment. In the case of AISI 316Ti titanium carbides $\mathrm{TiC}$ where present in the structure.

Table 1. Chemical composition of austenitic stainless steels [in weight \%]

\begin{tabular}{|c|c|c|c|c|c|c|c|c|c|}
\hline Element & $\mathbf{C}$ & $\mathbf{C r}$ & $\mathbf{N i}$ & $\mathbf{M o}$ & $\mathbf{M n}$ & $\mathbf{S i}$ & $\mathbf{S}$ & $\mathbf{P}$ & $\mathbf{T i}$ \\
\hline AISI 304 & 0.05 & 19.59 & 7.84 & 0.49 & 1.57 & 0.29 & 0.03 & 0.05 & - \\
\hline AISI 316L & 0.03 & 17.41 & 9.91 & 2.38 & 1.34 & 0.51 & 0.03 & 0.07 & - \\
\hline AISI 316Ti & 0.03 & 17.83 & 10.62 & 2.36 & 1.54 & 0.44 & 0.03 & 0.06 & 0.14 \\
\hline
\end{tabular}

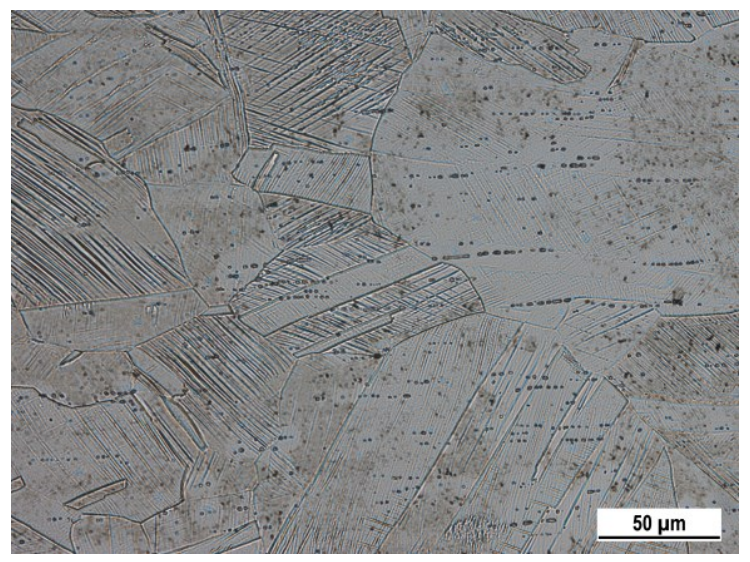

Fig. 1. Microstructure of AISI 304 in initial state 


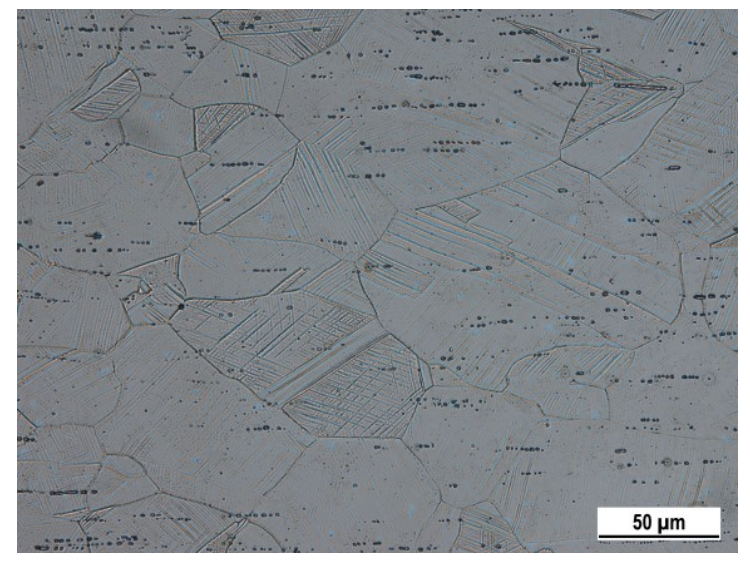

Fig. 2. Microstructure of AISI $316 \mathrm{~L}$ in initial state

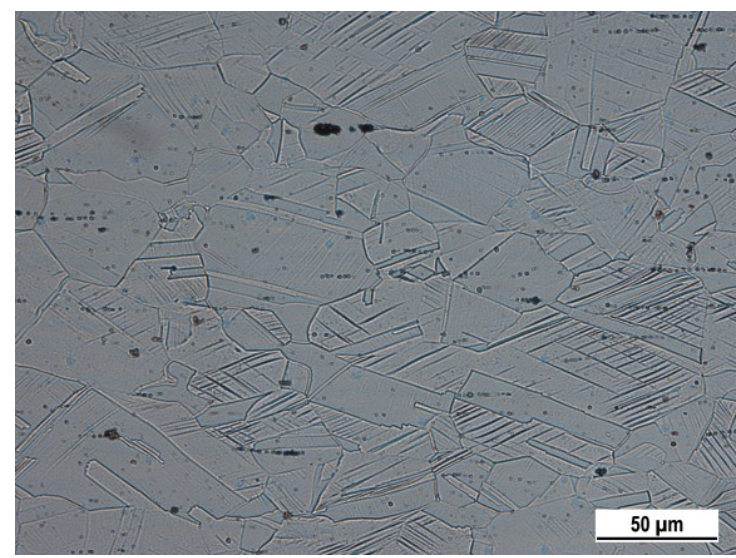

Fig. 3. Microstructure of AISI $316 \mathrm{Ti}$ in initial state

\subsection{Experimental equipment}

The experimental equipment consists of mechanical and electronical part and is shown on the Fig. 4. The mechanical part (Fig. 5a) consists of three basic parts: the transducer, which serves like the source and at the same time like detector of ultrasonic waves. Then the rod, which is made of titanium and has a cylindrical shape with a diameter of $12 \mathrm{~mm}$. Its function is to isolate the heat from the test specimen, which is heated in a furnace and the transducer then maintains at a constant room temperature. And the last part is the testing specimen (Fig. 5b). Dimensions and shape of the test specimen are designed to fulfill the resonance condition, that means the natural frequency must be approximately the same like the frequency of the test equipment $\pm 10 \mathrm{~Hz}$. 


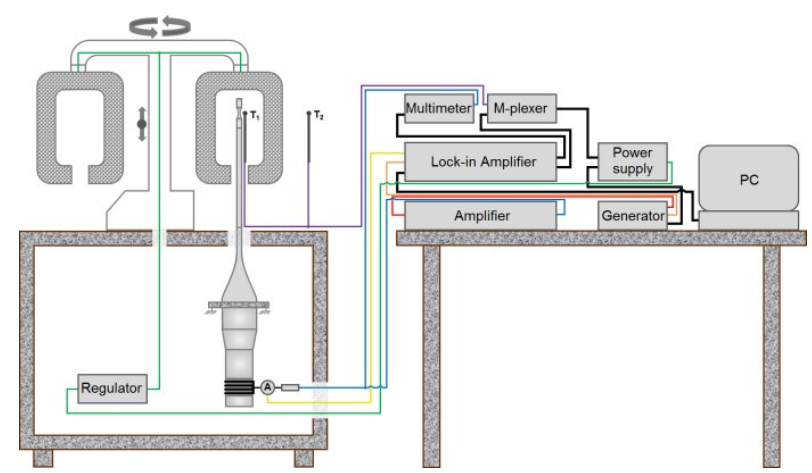

Fig. 4. Ultrasonic resonance device for internal damping measurement

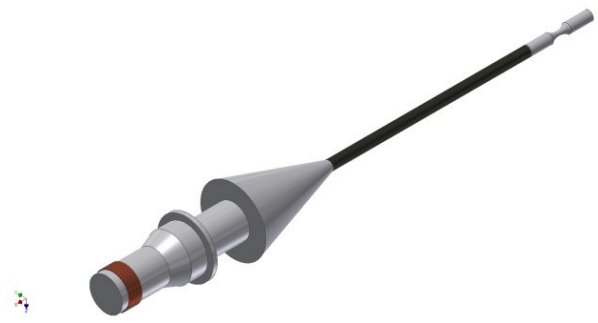

(a)

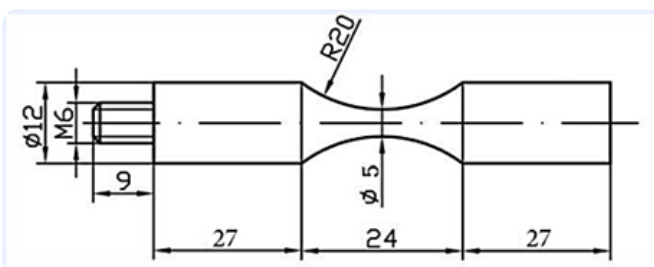

(b)

Fig. 5. Mechanical part of the device (a); dimensions of the specimen (in $\mathrm{mm}$ ) (b)

\section{Results and discussion}

The Fig. 6 to the Fig. 11, documents the results of the internal damping measurement of austenitic stainless steel AISI 304, AISI 316L and AISI 316Ti in intial state and after plastic deformation depending on the temperature.

In the Fig. 6, Fig. 8 and Fig. 10 are presented results of internal damping in initial state after first measurement, where the peak of internal damping during the heating is in the temperature range of $80-100{ }^{\circ} \mathrm{C}$. Also these graphs contains the second measurement of internal damping, on the same samples, where not such a high peak was observed as in the first measurement. This fact that in the second measurement is no significant peak is related to the movement of disslocations and energy dissipation which has taken place during the first measurement.

All the testing samples were heated from room temperature upto $400{ }^{\circ} \mathrm{C}$ and followed by reverse cooling. Further heating above $400{ }^{\circ} \mathrm{C}$ was not necessary because all the processes has taken place in the temperature range of $25-100{ }^{\circ} \mathrm{C}$. After this interval there is a steep decline of internal damping and after $200{ }^{\circ} \mathrm{C}$ the values of internal damping change only a little.

The highest value of internal damping, the local maximum, was reached in the temperature range $80-100{ }^{\circ} \mathrm{C}$ where deformation-induced martensite transforms to austenite [6]. The highest local maximum was observed within the AISI 316Ti testing sample. In the backward measurement, cooling, the value of internal damping is lower in comparison with starting value and there is no local maximum reached.

In the Fig. 7, Fig. 9 and Fig. 11 are presented results of internal damping after plastic deformation. The graphs also presents the first and second measurement of internal damping showing that there was an increase of damping values again in the range of $80-$ $100{ }^{\circ} \mathrm{C}$. This increase indicates that microplastic deformation which causes irreversible 
movemet increases the disslocation density in small volumes of the steel and causes strengthening which leads to creation of deformation martensite. This local maximum of internal damping is a result of deformation-induced martensite transformation to austenite [7].

By heating the steel, a reversible process begins, in which the elastic deformation is removed and then the stress in the deformed grains is reduced and relaxaction of disslocations begins in the disslocation accumulated grains. The deformation-induced martensite transformation into austenite is accompanied by migration and reduction of vacancies an creation of additional lattice imperfections [8]. The reverse process is then accompanied by the formation of annealing twins where the accumulated excessive energy is reduced [9]. The plastic deformation also changes magnetic properties because deformation-induced martensite has slightly feromagnetic properties [10].

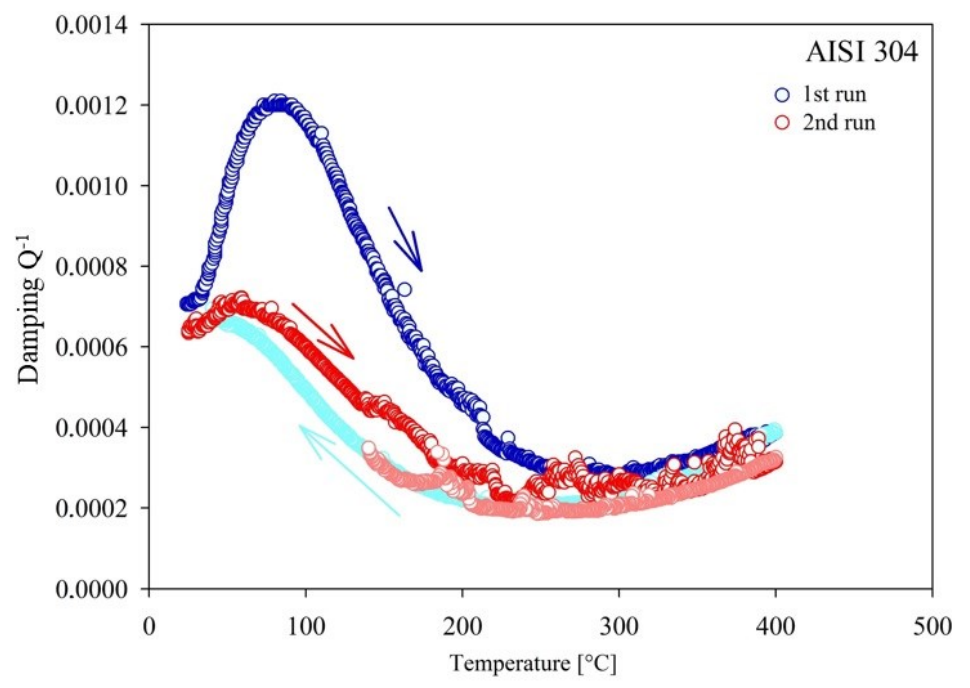

Fig. 6. Results of internal damping measurement of AISI 304 in initial state

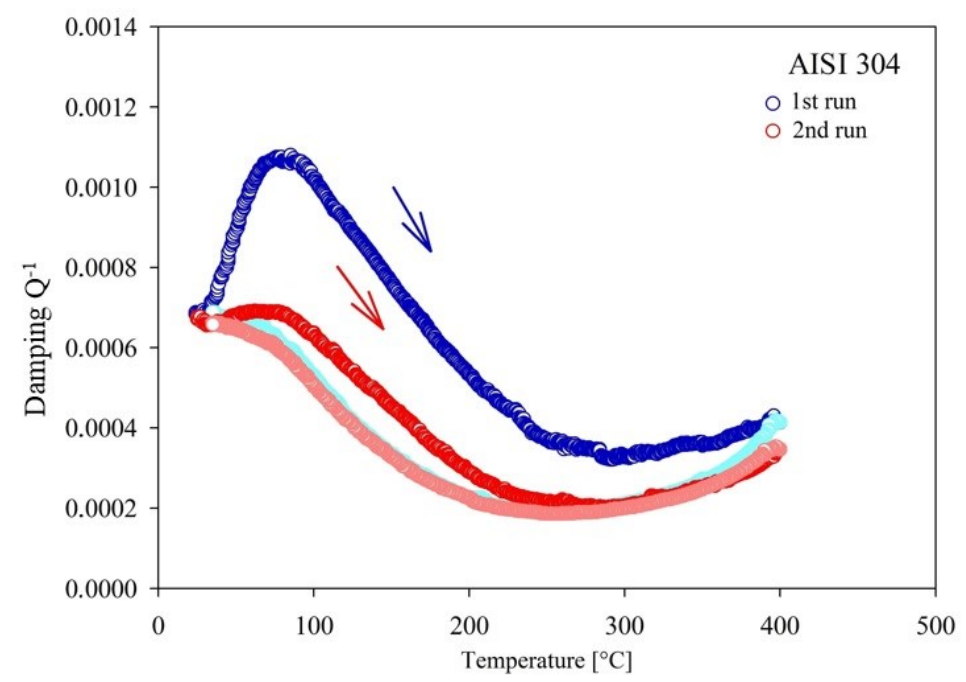

Fig. 7. Results of internal damping measurement of the deformed AISI 304 


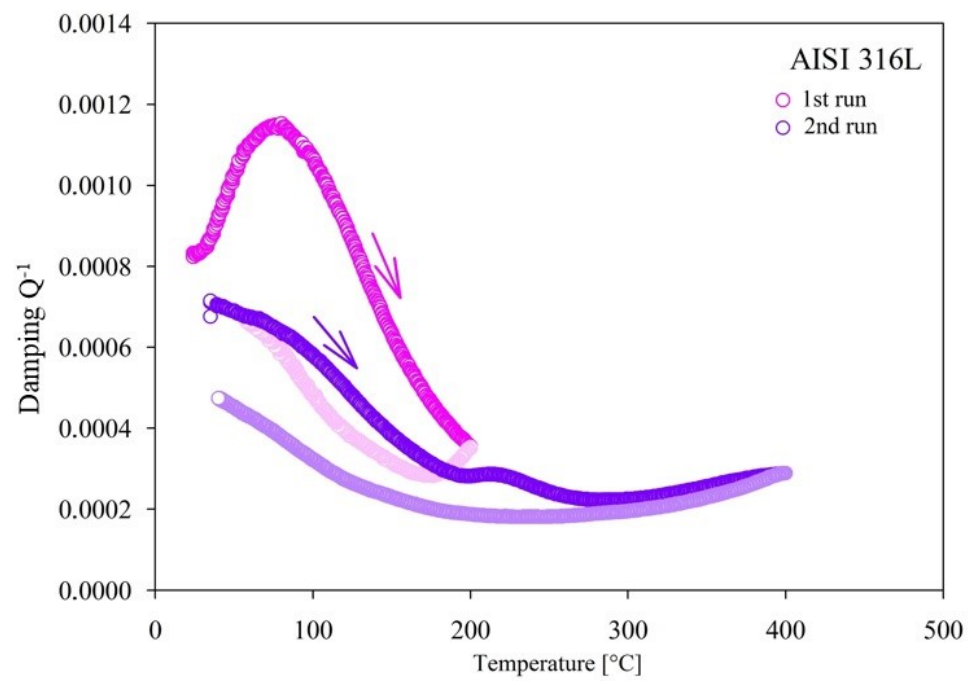

Fig. 8. Results of internal damping measurement of AISI $316 \mathrm{~L}$ in initial state

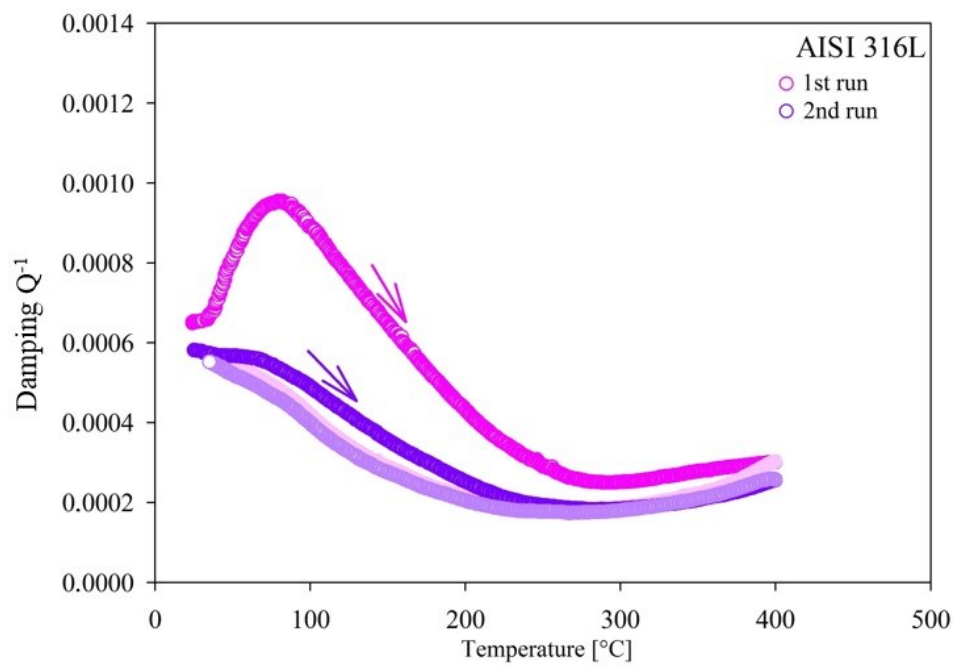

Fig. 9. Results of internal damping measurement of the deformed AISI $316 \mathrm{~L}$ 


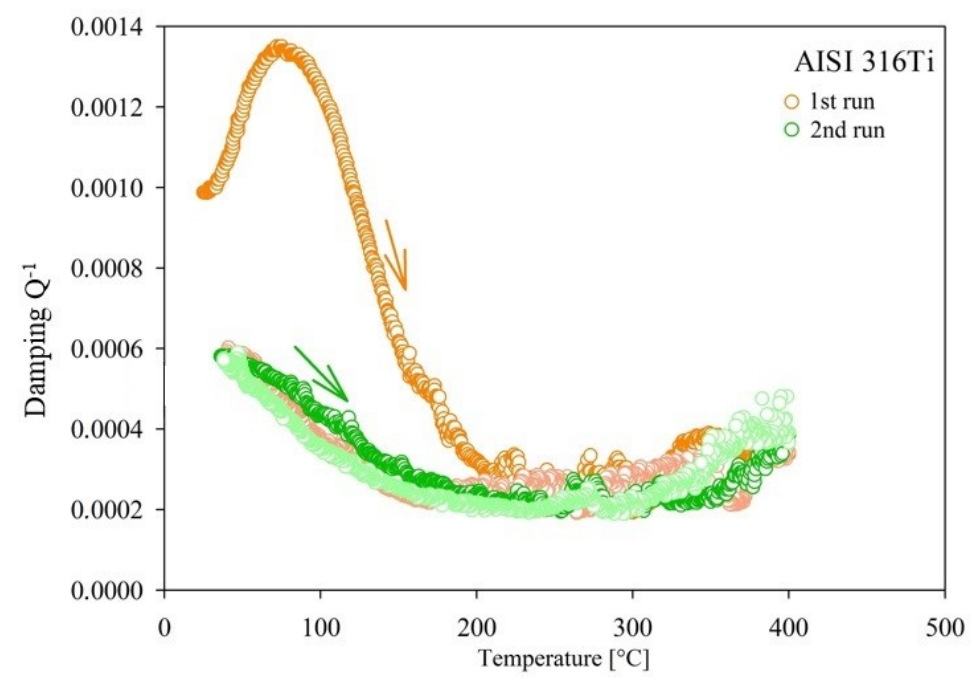

Fig. 10. Results of internal damping measurement of AISI $316 \mathrm{Ti}$ in initial state

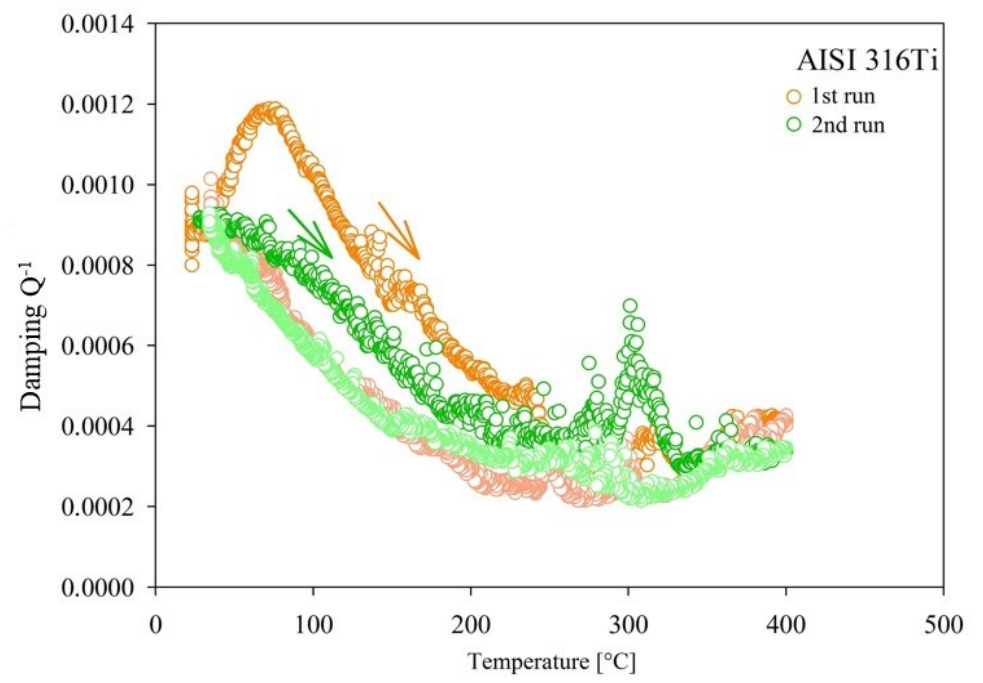

Fig. 11. Results of internal damping measurement of the deformed AISI $316 \mathrm{Ti}$

\section{Conclusion}

Based on experimental results from internal damping measurements of austenitic stainless steels AISI 304, AISI 316L and AISI 316Ti can be stated:

- The peak of internal damping during the heating was in the temperature range of $80-100{ }^{\circ} \mathrm{C}$ for all the experimental material.

- We can conclude that all relaxation process has taken place during the first measurement.

- No significant local maximum was observed during second measurement nor during the cooling phase. 
- An increase of internal damping values in the case of plastically deformed testing samples was observed again in the range of $80-100{ }^{\circ} \mathrm{C}$.

- The noticed peak during the measurement in austenitic stainless steels are based on the fact if the material is plastically deformed during cold working or not.

- Deformation-induced martensite initiates the steel's strengthening and the dislocation density is higher at the grain boundary than in its bulk.

- The reversed process was accompanied by the formation of annealing twins where the accumulated excessive energy was reduced.

This work has been supported by Scientific Grant Agency of Ministry of Education of Slovak Republic and Slovak Academy of Sciences, No. 1/0683/15.

\section{References}

1. M. F. McGuire, Stainless steels for design engineers. ASM International (2008)

2. V. Č́ihal, Korozivzdorné oceli a slitiny. Academia Praha (1999)

3. T. F. A. Santos, M. S. Andrade, Internal Friction on AISI 304 Stainless Steels with Low Tensile Deformations at Temperatures between -50 and $20{ }^{\circ} \mathrm{C}$. Advances in Materials Science and Engineering 2010, 1-8 (2010)

4. R. Singh, B. Ravikumar, A. Kumar, P. K. Dey, I. Chattoraj, The effect of cold working on sensitization and intergranular corrosion behaviour of AISI 304 stainless steel. Springer Publishing: Metallurgical and Materials Transactions A 34, 2441-2447 (2003)

5. J. Talonen, H. Hänninen, Damping properties of austenitic stainless steels containing strain-induced martensite. Metallurgical and Materials Transactions A 35A, 2401-2406 (2004)

6. N. Solomon, I. Solomon, Deformation induced martensite in AISI 316 stainless steel. Revista de Metalurgia 46, 121-128 (2010)

7. P. Hedström, Deformation and Martensitic Phase Transformation in Stainless Steels. Doctoral thesis. Luleå University of Technology (2007)

8. E. Dryzek, M. Sarnek, M. Wróbel, Reverse transformation of deformation-induced martensite in austenitic stainless steel studied by positron annihilation. Springer US 49, 8449-8458 (2014)

9. Y. Jin, M. Bernacki, G. S. Rohrer, A. D. Rollett, B. Lin, N. Bozzolo, Formation of annealing twins during recrystallization and grain growth in $304 \mathrm{~L}$ austenitic stainless steel. Materials Science Forum 753, 113-116 (2013)

10. T. Oršulová, P. Palček, J. Kúdelčík, Effect of plastic deformation on the magnetic properties of selected austenitic stainless steels. Production Engineering Archives 14, $15-18$ (2017) 